\title{
A ASSISTÊNCIA DOS PROFISSIONAIS DE SAÚDE NO PARTO HUMANIZADO
}

\author{
Olavo Maurício de Souza Neto ${ }^{1}$, Luzianne Teotonio Cavalcanti ${ }^{1}$, Débora Thaise \\ Freires de Brito², Gigliola Marcos Bernardo de Lima33. \\ ${ }^{1}$ Curso de Bacharelado em Enfermagem, Unidade Acadêmica de Enfermagem, Universidade \\ Federal de Campina Grande, Cuité-PB, Brasil. \\ ${ }^{2}$ Enfermeira. Especialista em Saúde da Família e Comunidade. Mestranda em Saúde Coletiva \\ pela Universidade Federal da Paraíba/UFPB \\ ${ }^{3}$ Prof ${ }^{a}$ Unidade Acadêmica de Enfermagem, Universidade Federal de Campina Grande, Cuité, \\ PB, Brasil. \\ Email para correspondência: olavomauricio128@gmail.com
}

\begin{abstract}
Resumo
O estudo em tela tem por objetivo analisar, a partir da literatura pertinente, a assistência dos profissionais de saúde no parto humanizado. Optou-se pelo método de revisão integrativa da literatura, cuja pergunta norteadora foi: como se dá a assistência dos profissionais de saúde no parto humanizado? Nessa perspectiva, os critérios de inclusão foram artigos disponíveis na íntegra, nos idiomas português e inglês, no período de 2013 a 2018. Para seleção dos artigos, utilizaram-se as bases de dados Biblioteca Virtual em Saúde (BVS), Medical Literature Analysisand Retrieval System Online (MEDLINE), Literatura LatinoAmericana e do Caribe em Ciências da Saúde (LILACS), Base de Dados de Enfermagem (BDENF) e Pubmed. Foram utilizados como descritores: Profissionais de saúde, Parto Humanizado e Obstetrícia, associados de dois em dois e a posteriori os quatros juntos, pelo operador booleano AND para aumentar as possibilidades de busca. Verificou-se uma grande necessidade de especialização da enfermagem obstétrica, existindo escassez de estudos nessa área. Observou-se fragilidade na assistência dos profissionais de saúde, presumindo-se de mudanças na prestação de serviços para que a autonomia da mulher seja respeitada.
\end{abstract}

Palavras-chave: Profissionais de Saúde, Parto Humanizado, Obstetrícia.

\begin{abstract}
The study on screen aims to analyze, from the relevant literature, the assistance of non-humanized health professionals. Opt for the method of integrative literature review, whose question to the north was: how does professional humanized health care provide? In this perspective, candidates for inclusion of articles available in full, in Portuguese and English, from 2013 to 2018. For selection of articles, Virtual Health Library $(\mathrm{VHL})$, Medical Literature Analysis and Retrieval databases are used System Online (MEDLINE), Latin American and Caribbean Health Sciences Literature (LILACS), Nursing Database (BDENF) and Pubmed. The following descriptors were used: Health professionals, Humanized Childbirth and Obstetrics,
\end{abstract}


associated two by two and later to quarters together, by the Boolean operator $E$ to increase search possibilities. There was a great need for specialization in obstetric nursing, with a lack of studies in this area. Observe the fragility in the assistance of health professionals, assuming changes in the provision of services so that the autonomy of women is respected.

Keywords: Health professionals, Humanized Birth, Midwifery.

\section{Introdução}

Conforme os anos foram se passando, novas práticas foram sendo inseridas no processo do parto, incluindo a utilização de medicamentos que aceleram o processo de parturição. Com os avanços técnicos-científicos e o desenvolvimento da medicina, a gravidez e o nascimento se tornaram um evento hospitalar (POSSATI et al., 2017).

Um estudo feito por Andrade et al., (2014), realizado no Instituto de Medicina Integral Professor Fernando Figueira, um hospital-escola de alta complexidade e de referência do Ministério da Saúde (MS) para a assistência materno infantil em Recife/Pernambuco, com 603 puérperas, aponta que a prevalência de violência obstétrica foi de $86,57 \%$. As práticas prejudiciais mais frequentes foram os esforços de puxo, a administração de ocitocina e o uso rotineiro da posição supina/litotômica. Com base nesses dados, se evidencia a precária assistência humanizada no parto pelos profissionais da saúde, em contradição ao preconizado pelo MS, em 2000, quando foi lançado o Programa de Humanização do Pré-natal e Nascimento.

$\mathrm{Na}$ década de 1980, ganhou-se visualidade a mobilização da humanização do parto que, além do atendimento acolhedor e atencioso à parturiente, sugeriu-se a assistência baseada em indícios científicos, um dos pontos mais importantes da passagem para mudança do modelo assistencial obstétrico brasileiro (SOUSA et al., 2016).

Nesse sentido, a humanização se faz necessária e concerne na necessidade de um novo olhar, onde o acolher, o ouvir, o aconselhar, o contato com o outro é uma experiência humana e que se torna fundamental para as mulheres que estão passando pela gestação e pelo processo do parto. Envolvendo práticas, atitudes e condutas, que auxilia nesse processo, valorizando e respeitando a autonomia da mulher e compreender o tempo 
individual de cada uma, sem utilizar procedimentos desnecessários, como a utilização de medicamentos para induzir o parto (POSSATI et al., 2017).

Nesse contexto, a humanização do parto interferiu de maneira positiva, pois é notável a importância da participação das parturientes, conforme a necessidade de cada uma, tendo a conservação do parto como um acontecimento natural e fisiológico, na qual a mulher é assistida por profissionais de saúde, tendo preservados os seus direitos como cliente e como ser humano (POSSATI et al., 2017).

Diante dessa discussão e visando a sua importância, esse estudo sobreveio com a seguinte pergunta norteadora: Como se dá a assistência dos profissionais de saúde no parto humanizado? Assim, frente ao questionamento, esse estudo tem por objetivo geral, analisar a partir das pesquisas publicadas referente a temática em questão, a assistência dos profissionais de saúde no parto humanizado, como objetivos específicos, compreender a importância da humanização do parto atualmente e relatar por meio das pesquisas, no espaço entre 2014 à 2018 como está essa assistência dos profissionais de saúde nesse limite temporal.

\section{Metodologia}

\subsection{Tipo de estudo}

A metodologia de um trabalho ilustra todo o procedimento realizado durante uma pesquisa, as técnicas e os materiais que foram utilizados para a construção do trabalho (ESTRELA, 2018, p: 149). O presente estudo trata-se de uma revisão integrativa da literatura.

A revisão integrativa de literatura é uma ferramenta dos inúmeros métodos científicos, tendo como objetivo resumir resultados alcançados em pesquisas sobre uma temática em questão, de maneira sistemática, ordenada e abrangente. E tem essa denominação integrativa, porque fornece conhecimentos mais amplos sobre o problema ou assunto em questão. Sendo assim, o pesquisador pode efetuar uma revisão integrativa com várias finalidades, na qual pode ser direcionada à definição de teorias, conceitos, análises metodológicas, e outros (ERCOLE; MELO; ALCOFORADO, 2014). 


\subsection{Delineamento do estudo}

Os critérios de inserção amostral seguiram uso de periódicos nacionais e internacionais como o Pubmed, por meio da Biblioteca Virtual em Saúde (BVS), foi possível explorar artigos nas bases de dados como a Medline, Lilacs e Bdenf. A pesquisa foi realizada na Universidade Federal de Campina Grande/UFCG, no Centro de Educação e Saúde/CES, Campus Cuité.

A pesquisa utilizou alguns critérios de inclusão, como os artigos disponíveis referentes à temática dos últimos quatro anos (2014-2018) nos idiomas, português e inglês. Os Descritores em Ciências da Saúde (DeCS) proporcionou o acesso das palavras cadastradas que facilitam a pesquisa em bases de dados, como por exemplo, as bases citadas anteriormente. Nos DeCS, encontrou-se "Profissionais de saúde", "Parto Humanizado" e "Obstetrícia", que foram de suma importância na filtragem de artigos na pesquisa.

Os parâmetros de eliminação foram os artigos repetidos, que não se encaixava no contexto da pesquisa.

\subsection{Instrumentos e coleta de dados}

A pesquisa bibliográfica foi realizada no período de janeiro a março de 2018. O instrumento foi composto de variáveis que compusessem um quadro com os itens: autor, ano, objetivos, resultados para a coleta de dados, a literatura disponível sobre a temática em questão, que são as referências aplicadas neste trabalho, onde serviram de embasamento teórico para elaboração do mesmo.

Para filtragem dos artigos nas bases de dados nacionais e internacionais, utilizou-se 0 indicador booleano $A N D$ no cruzamento dos descritores, com intuito de especificar e filtrar a pesquisa, para que se utilizassem os artigos que mais se relaciona com o assunto em questão.

\subsection{Processamento e análise de dados}

Pesquisou-se na BVS e no Pubmed com a finalidade de integrar esse estudo, onde a identificação dos artigos se deu por meio dos descritores de maneira individual. O primeiro descritor foi "Profissionais da Saúde" que obteve-se um 
total de 107.789 artigos na BVS, e depois da inserção do filtro como critério de inclusão ficaram 18.459, sendo desses, 13.715 encontrados na Medline, 3.552 no Lilacs e 1.993 na Bdenf. Já na Pubmed foram encontrados 666.189 e com a inserção do filtro 122.568.

O segundo descritor utilizado foi "Parto Humanizado" onde foram encontrados 1.132 na BVS, depois que foi inserido o filtro, restaram 228, e desses nenhum na Medline, 123 no Lilacs e 131 na Bdenf. Já na Pubmed foram encontrados 304 , e com o filtro 82 , e o terceiro descritor foi "Obstetrícia" sendo encontrados na BVS 27.408, após o filtro, 4.578 e desses, 4.330 na Medline, 179 no Lilacs, e 99 na Bdenf. E, no pubmed foram encontrados 49.982, e com o filtro, 16.727.

$\mathrm{Na}$ realização dos cruzamentos dos descritores utilizou-se o indicador booleano "AND". Ressaltando-se que todos os cruzamentos já foram feitos com o filtro, alcançando-se a seguinte disposição na BVS: "Profissionais de saúde AND Parto Humanizado" (68 artigos), dispondo-se no Lilacs com (38), (39) na Bdenf e nenhum na Medline. E, no Pubmed foram encontrados 5 artigos.

No cruzamento com os descritores "Profissionais de saúde AND Obstetrícia" obteve-se 309 distribuídos na Medline com 248 artigos, Lilacs (38) e Bdenf (31) artigos. No Pubmed foram encontrados 4.212 artigos.

Com o cruzamento "Parto Humanizado AND Obstetrícia" obteve-se 59 artigos, distribuídos no Lilacs com (31) na Bdenf com (30) e nenhum na Medline e, no Pubmed, foram encontrados (5 artigos).

Ao cruzar os três descritores, que foi definido como situação ideal para responder aos objetivos desse estudo, foi encontrado um total de 28 artigos, somados os artigos encontrados na BVS e Pubmed, já com o critério de inclusão. Quando se incluiu os critérios de exclusão que foram aqueles que se repetiram em mais de uma base de dados e que não se relacionavam com 0 tema, totalizou no final 18 artigos. 
QUADRO 1: Descrição do processamento e análise dos dados na Biblioteca Virtual em Saúde (BVS):

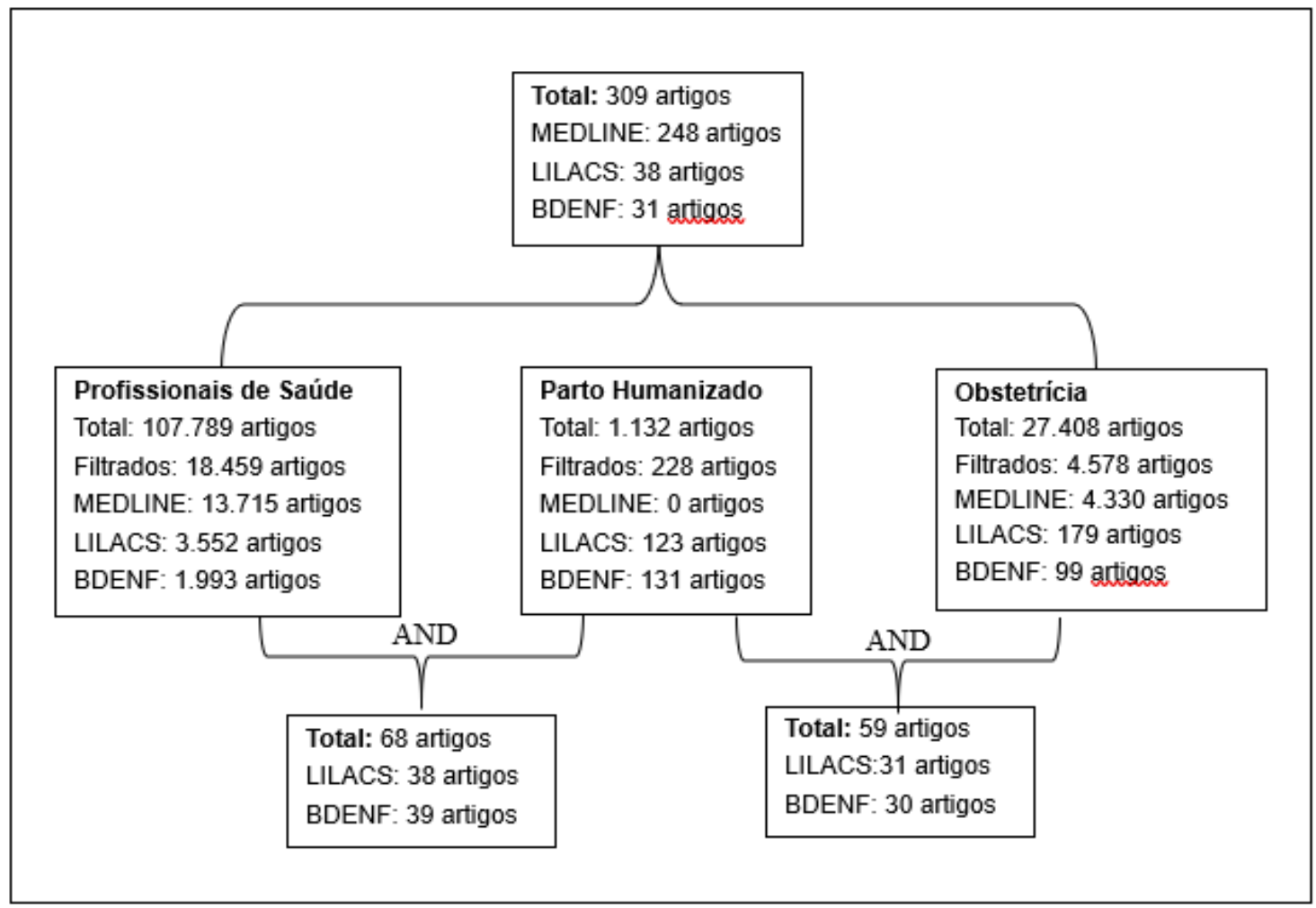

Fonte: Dados da pesquisa, 2019.

QUADRO 2: Descrição do processamento e análise dos dados no Pubmed

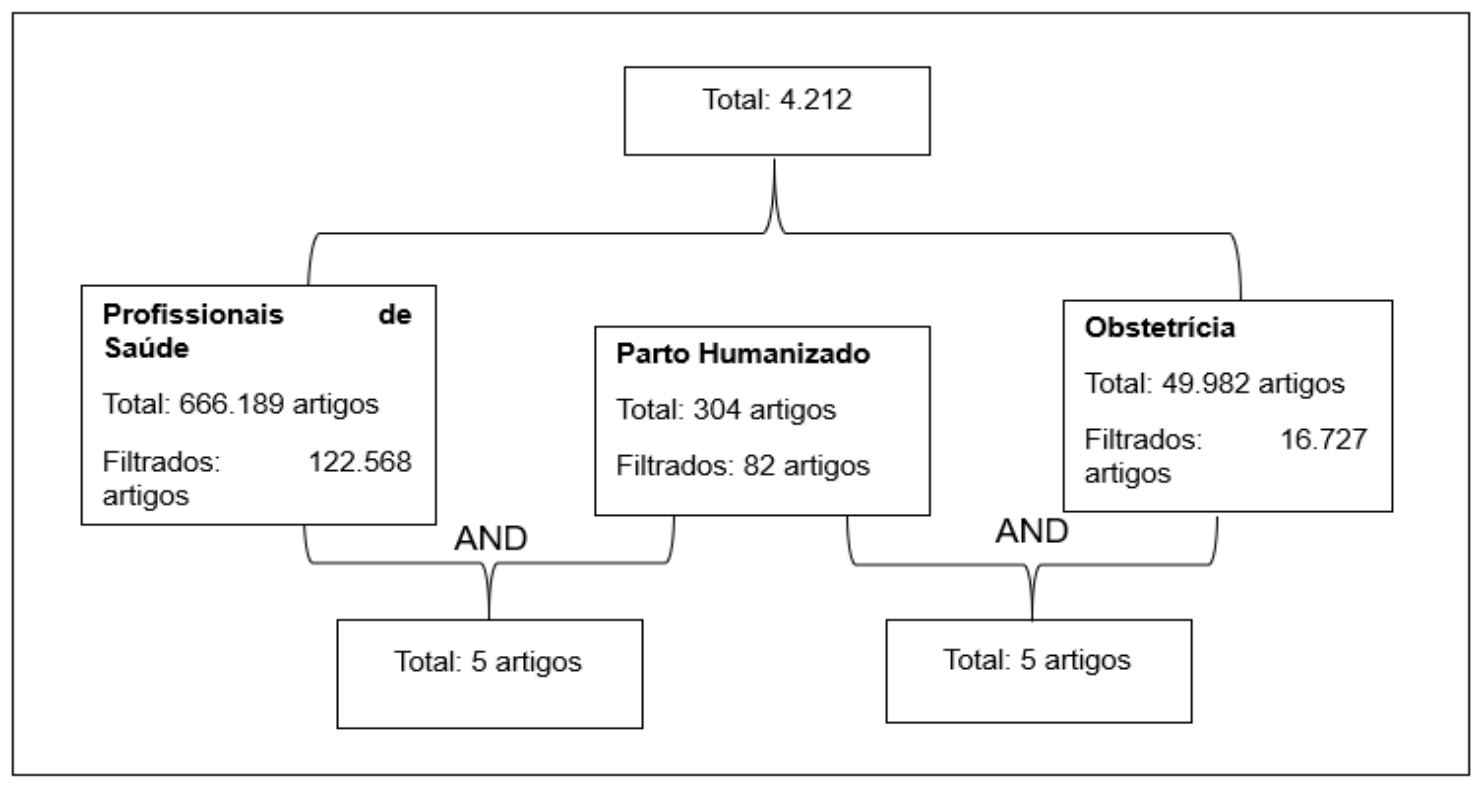

Fonte: Dados da pesquisa, 2019. 
QUADRO 3: Descrição do processamento e análise dos dados já com as somas dos artigos encontrados na BVS e Pubmed.

\begin{tabular}{|c|c|c|}
\hline \multicolumn{3}{|c|}{ Profissionais de Saúde AND Parto Humanizado AND Obstetrícia } \\
\hline $\begin{array}{l}\text { Total: } 65 \text { artigos } \\
\text { Filtrados: } 28 \text { artigos }\end{array}$ & Critérios de inclusão + Critérios de exclusão = 18 Artigos & $\begin{array}{l}\text { BVS: } \\
\text { MEDLINE = } 0 \text { artigos } \\
\text { LILACS = } 11 \text { artigos } \\
\text { BDENF = } 15 \text { artigos }\end{array}$ \\
\hline
\end{tabular}

Fonte: Dados da pesquisa, 2019.

\section{$3 \quad$ Resultados}

$\mathrm{Na}$ tabela 1, serão apresentados os artigos referentes à temática de acordo com o título do artigo, objetivos e os principais resultados encontrados. Para uma melhor sistematização, os artigos serão organizados de acordo com o ano de publicação.

TABELA 1: Apresentação dos artigos selecionados de acordo com o ano de publicação, título, objetivos e principais resultados.

\begin{tabular}{|c|c|c|}
\hline TÍTULO & OBJETIVOS & PRINCIPAIS RESULTADOS \\
\hline \multicolumn{3}{|l|}{2014} \\
\hline $\begin{array}{lr}\text { Direito } & \text { das } \\
\text { parturientes: } & 0 \\
\text { conhecimento } & \text { da } \\
\text { adolescente } & \text { e } \\
\text { acompanhante. } & \end{array}$ & $\begin{array}{l}\text { Analisar o conhecimento } \\
\text { de adolescentes e seus } \\
\text { acompanhantes acerca } \\
\text { dos seus direitos no } \\
\text { parto }\end{array}$ & $\begin{array}{l}\text { A maioria dos entrevistados não possuíam } \\
\text { conhecimento sobre seus direitos, e o que } \\
\text { conheciam era o direito a acompanhante. Em } \\
\text { relação a atenção recebida pelos profissionais } \\
\text { de saúde foi considerada precária, já que as } \\
\text { usuárias se demostraram passivas justamente } \\
\text { por falta desse conhecimento, não os } \\
\text { reivindicando, fazendo com que mudanças na } \\
\text { assistência prestada seja diminuída. }\end{array}$ \\
\hline $\begin{array}{l}\text { Violência obstétrica } \\
\text { na visão de } \\
\text { enfermeiras } \\
\text { obstetras. }\end{array}$ & $\begin{array}{l}\text { Relatar a experiência de } \\
\text { enfermeiras obstetras } \\
\text { sobre a violência } \\
\text { obstétrica vivenciada, } \\
\text { presenciada } \\
\text { observada durante suas } \\
\text { trajetórias profissionais. }\end{array}$ & $\begin{array}{l}\text { Constatou-se que inúmeras violências } \\
\text { obstétricas vivenciadas e presenciadas em } \\
\text { suas rotinas de trabalho, havendo diferenças } \\
\text { entre dois tipos de assistência ao parto: a } \\
\text { obstetrícia baseada em evidências e o modelo } \\
\text { assistencial tradicional. }\end{array}$ \\
\hline \multicolumn{3}{|l|}{2015} \\
\hline $\begin{array}{l}\text { Associação entre } \\
\text { as boas práticas de } \\
\text { assistência ao } \\
\text { trabalho de parto e } \\
\text { parto e a avaliação } \\
\text { pelas puérperas do } \\
\text { cuidado recebido. }\end{array}$ & $\begin{array}{l}\text { Avaliar a associação } \\
\text { entre a adoção das } \\
\text { boas práticas na } \\
\text { assistência ao trabalho } \\
\text { de parto e parto e a } \\
\text { avaliação do pelas } \\
\text { puérperas do cuidado } \\
\text { recebido }\end{array}$ & $\begin{array}{l}\text { Observou-se a diferença da assistência em } \\
\text { relação a rede privada e a rede pública. A } \\
\text { assistência na rede privada foi mais positiva } \\
\text { em relação, a assistência prestada pelo } \\
\text { Sistema Único de Saúde (SUS). } \\
\text { Evidenciando-se a desigualdade da qualidade } \\
\text { na assistência entre os dois setores. Outro } \\
\text { ponto relevante, é que a maiorias das }\end{array}$ \\
\hline
\end{tabular}




\begin{tabular}{|c|c|c|}
\hline & & $\begin{array}{l}\text { mulheres entrevistadas não possuíam } \\
\text { conhecimento acerca dos seus direitos. Foi } \\
\text { constatado que a assistência na na região } \\
\text { Sudeste do Brasil não está de acordo com o } \\
\text { que foi preconizado pela Organização Mundial } \\
\text { de Saúde (OMS) e o Ministério da Saúde } \\
\text { (MS). }\end{array}$ \\
\hline $\begin{array}{lr}\text { Obstetrícia em } & \text { um } \\
\text { momento } & \text { de } \\
\text { violência: parteira } \\
\text { mexicana } \\
\text { práticas de rotica } \\
\text { do hospital. }\end{array}$ & 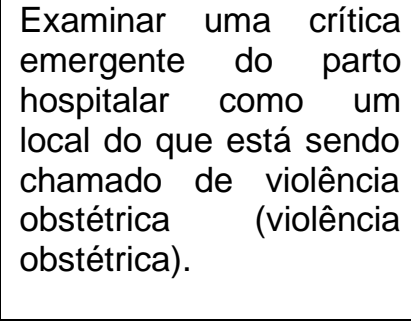 & $\begin{array}{l}\text { Constatou-se que a violência obstétrica no } \\
\text { México acontece de maneira corriqueira em } \\
\text { hospitais públicos, como se fosse normal. } \\
\text { Evidenciando a precariedade na assistência } \\
\text { dos profissionais de saúde. Com o auxílio } \\
\text { das parteiras, e sua inserção no ambiente } \\
\text { hospitalar, tenta-se sensibilizar e humanizar os } \\
\text { profissionais de saúde. }\end{array}$ \\
\hline \multicolumn{3}{|r|}{ ( } \\
\hline $\begin{array}{ll}\text { Implementação } & \text { da } \\
\text { humanização } & \text { da } \\
\text { assistência } & \text { ao } \\
\text { parto natural. } & \\
\end{array}$ & $\begin{array}{l}\text { Analisar a } \\
\text { implementação das } \\
\text { práticas humanizadas } \\
\text { na assistência ao parto } \\
\text { natural, fundamentada } \\
\text { no documento "Boas } \\
\text { práticas de atenção ao } \\
\text { parto e ao nascimento" } \\
\text { de } 1996\end{array}$ & $\begin{array}{l}\text { Pôde-se perceber ao longo da pesquisa que } \\
\text { ouve a prática da humanização no parto de } \\
\text { modo geral, onde a maioria das parturientes } \\
\text { relataram contentamento com a assistência } \\
\text { que receberam, e que na maioria dos partos } \\
\text { não foi necessário a aplicação de } \\
\text { medicamentos. Tiveram o apoio empático dos } \\
\text { profissionais de saúde. Respeitando a } \\
\text { liberdade da mulher. }\end{array}$ \\
\hline $\begin{array}{l}\text { Motivos } \\
\text { formação e atuação } \\
\text { profissional: } \\
\text { percepção } \\
\text { Doulas. }\end{array}$ & $\begin{array}{l}\text { Analisar os fatores } \\
\text { motivacionais para } \\
\text { mulheres buscarem a } \\
\text { formação de doula e } \\
\text { desenvolverem suas } \\
\text { atividades profissionais. }\end{array}$ & $\begin{array}{l}\text { Evidenciou-se a importância de formação de } \\
\text { doulas, que são as profissionais que dão apoio } \\
\text { e suporte emocional as parturientes, onde em } \\
\text { alguns relatos do estudo, a assistência ao } \\
\text { parto no serviço público de saúde é deficiente } \\
\text { por não respeitar a autonomia da mulher. }\end{array}$ \\
\hline $\begin{array}{l}\text { O sensível e o } \\
\text { insensível na sala } \\
\text { de } \quad \text { parto: } \\
\text { interdiscursos de } \\
\text { profissionais de } \\
\text { saúde e mulheres. }\end{array}$ & $\begin{array}{l}\text { Analisar os discursos } \\
\text { sobre a assistência ao } \\
\text { parto na perspectiva de } \\
\text { mulheres e profissionais } \\
\text { de saúde de uma rede } \\
\text { pública, considerando } \\
\text { as experiências } \\
\text { vivenciadas na } \\
\text { interação construída } \\
\text { durante o trabalho de } \\
\text { parto e parto }\end{array}$ & $\begin{array}{l}\text { Evidenciou-se que a violência obstétrica se faz } \\
\text { presente no cotidiano da sala de parto, sendo } \\
\text { uma realidade silenciada pelos enfermeiros, } \\
\text { consentida pelas mulheres pela falta de } \\
\text { esclarecimento sobre seus direitos e } \\
\text { negligenciada pelos profissionais médicos, } \\
\text { que age como se esse ato não tivesse } \\
\text { grandes proporções. }\end{array}$ \\
\hline $\begin{array}{lr}\text { Avaliação } & \text { da } \\
\text { implementação do } \\
\text { modelo de serviços } \\
\text { integrados r de } \\
\text { saúde e obstetrícia } \\
\text { humanizados no } \\
\text { Chile. }\end{array}$ & $\begin{array}{l}\text { Garantir o acesso de } \\
\text { todas as mulheres } \\
\text { grávidas no Chile a } \\
\text { assistência profissional } \\
\text { durante o trabalho de } \\
\text { parto e parto, de forma } \\
\text { segura e personalizada. } \\
\text { fortalecendo a relação } \\
\text { entre paciente e } \\
\text { profissional. }\end{array}$ & $\begin{array}{l}\text { Pode-se observar que a maioria das mulheres } \\
\text { entrevistadas em nove hospitais regionais } \\
\text { públicos no Chile não estão recebendo } \\
\text { cuidados atuais baseados em evidências. A } \\
\text { maioria das mulheres sentem que seu } \\
\text { atendimento é adequado, mas um terço delas } \\
\text { não. Existem a colaboração insuficiente dentro } \\
\text { da equipe obstétrica e uma boa comunicação, } \\
\text { que pode ser percebido pelas entrevistadas. } \\
\text { Existem fatores que prejudicam a } \\
\text { implementação do modelo humanizado de } \\
\text { cuidados em todas as regiões fazendo com } \\
\text { que a assistência seja inadequada. }\end{array}$ \\
\hline \multicolumn{3}{|l|}{2017} \\
\hline $\begin{array}{l}\text { O direito ao acesso } \\
\text { e acompanhamento } \\
\text { ao parto e e }\end{array}$ & \begin{tabular}{lr}
\multicolumn{2}{|c}{ Analisar as situações de } \\
violência & obstétrica \\
perpetrada & por
\end{tabular} & $\begin{array}{l}\text { Constatou-se o descumprimento dos direitos } \\
\text { básicos da mulher parturiente, como a recusa } \\
\text { ao acompanhante durante } 0 \text { parto, a }\end{array}$ \\
\hline
\end{tabular}




\begin{tabular}{|c|c|c|}
\hline $\begin{array}{l}\text { nascimento: a ótica } \\
\text { das mulheres. }\end{array}$ & $\begin{array}{l}\text { profissionais de saúde } \\
\text { durante o processo } \\
\text { parto/nascimento sob a } \\
\text { percepção das } \\
\text { puérperas acerca do } \\
\text { direito ao acesso à } \\
\text { maternidade e a ter um } \\
\text { acompanhante de sua } \\
\text { livre escolha }\end{array}$ & $\begin{array}{l}\text { dificuldade de acesso a maternidade e a falta } \\
\text { de humanização dos profissionais de saúde. }\end{array}$ \\
\hline $\begin{array}{l}\text { Parto humanizado } \\
\text { sob a ótica de } \\
\text { puérperas } \\
\text { atendidas em uma } \\
\text { maternidade } \\
\text { pública. }\end{array}$ & $\begin{array}{l}\text { Compreender } \\
\text { percepção a } \\
\text { puérperas, sobre o parto } \\
\text { humanizado, atendidas } \\
\text { em uma maternidade } \\
\text { pública. }\end{array}$ & $\begin{array}{l}\text { Evidenciou-se que a gestação e, } \\
\text { principalmente, o momento do parto, são } \\
\text { sempre um acontecimento que traz consigo } \\
\text { sentimentos como medo, dúvida, ansiedade e } \\
\text { dor, no entanto, também é uma experiência } \\
\text { extremamente gratificante, que traz emoções } \\
\text { inexplicáveis. Pode-se perceber que ainda há } \\
\text { falta de informação sobre o que é assistência } \\
\text { humanizada no pré-parto, parto e pós-parto. }\end{array}$ \\
\hline $\begin{array}{l}\text { O cuidado a mulher } \\
\text { no contexto da } \\
\text { maternidade: } \\
\text { caminhos } \\
\text { desafios para a } \\
\text { humanização. }\end{array}$ & $\begin{array}{lr}\text { Conhecer a percepção } \\
\text { de puérperas acerca da } \\
\text { atençãor recebida } \\
\text { durante a internação em } \\
\text { umarárlidade } \\
\text { pública. }\end{array}$ & $\begin{array}{l}\text { Foi evidenciado, pelo relato das mulheres a } \\
\text { importância de um acolhimento humanizado } \\
\text { pelos profissionais de saúde e do fácil acesso } \\
\text { ao serviço de saúde, que foram considerados } \\
\text { satisfatórios, pela maioria das entrevistadas, } \\
\text { no presente estudo. Porém, também foram } \\
\text { detectados problemas, pelas parturientes, } \\
\text { como falta de atenção no trabalho de parto, } \\
\text { falta de informação e comportamento } \\
\text { insensível de alguns profissionais da saúde. }\end{array}$ \\
\hline $\begin{array}{lr}\text { Práticas } & \text { de } \\
\text { assistência } & \text { ao } \\
\text { parto } & \text { normal: } \\
\text { formação } & \text { na } \\
\text { modalidade } & \text { de } \\
\text { residência. } & \end{array}$ & $\begin{array}{l}\text { Identificar as práticas } \\
\text { assistenciais realizadas } \\
\text { pelas residentes de } \\
\text { enfermagem obstétrica } \\
\text { durante a qualificação } \\
\text { profissional para o parto } \\
\text { normal e discutir as } \\
\text { práticas assistenciais } \\
\text { com base nas } \\
\text { recomendações } \\
\text { técnicas da } \\
\text { Organização Mundial de } \\
\text { Saúde }\end{array}$ & $\begin{array}{l}\text { A maioria das parturientes contou com } \\
\text { acompanhante; foi incentivada a realizar } \\
\text { técnicas de respiração, deambular e tomar } \\
\text { banho morno. A taxa de episiotomia foi baixa, } \\
5,1 \% \text {. As intervenções obstétricas no trabalho } \\
\text { de parto mais utilizada foi a ocitocina. Diante } \\
\text { dos resultados, observou-se que as } \\
\text { enfermeiras residentes realizam a maioria das } \\
\text { práticas obstétricas conforme as } \\
\text { recomendações técnicas. }\end{array}$ \\
\hline $\begin{array}{l}\text { Promoção da } \\
\text { saúde à mulher na } \\
\text { atenção ao parto: } \\
\text { comportamentos } \\
\text { específicos } \text { e } \\
\text { atuação ra da } \\
\text { enfermeira no } \\
\text { programa cegonha } \\
\text { carioca. }\end{array}$ & $\begin{array}{l}\text { Descrever as influências } \\
\text { narradas pelas } \\
\text { enfermeiras na Atenção } \\
\text { ao Parto no PCC; } \\
\text { caracterizar os } \\
\text { comportamentos que } \\
\text { determinam a atuação } \\
\text { das enfermeiras do PCC } \\
\text { na promoção da saúde } \\
\text { da mulher na atenção } \\
\text { ao parto e analisar a } \\
\text { atuação da enfermeira } \\
\text { do PCC na promoção } \\
\text { da saúde da mulher na } \\
\text { atenção ao parto. }\end{array}$ & $\begin{array}{l}\text { A enfermeira assume a responsabilidade de } \\
\text { desenvolver ações individuais e coletivas, de } \\
\text { sua competência legal e ética, visando à } \\
\text { qualidade de vida, autonomia e estímulo ao } \\
\text { autocuidado, principalmente por meio da } \\
\text { educação em saúde como prática aplicada em } \\
\text { todos os níveis de atenção e voltada à mulher, } \\
\text { família e comunidade. Por sua vez, isso } \\
\text { motiva mudanças de um paradigma } \\
\text { tecnocrático para um paradigma humanizado } \\
\text { na perspectiva da maternidade segura da } \\
\text { atenção ao parto normal. }\end{array}$ \\
\hline $\begin{array}{lr}\text { Relato } & \text { de } \\
\text { puérperas } & \text { acerca } \\
\text { da } & \text { violência }\end{array}$ & $\begin{array}{l}\text { Desvelar as formas de } \\
\text { violências obstétricas } \\
\text { sofridas durante a }\end{array}$ & $\begin{array}{l}\text { Observou- se que a dor, exames abusivos } \\
\text { repetitivos, manobras sem evidências } \\
\text { científicas de qualquer benefício e o descaso }\end{array}$ \\
\hline
\end{tabular}




\begin{tabular}{|c|c|c|}
\hline $\begin{array}{l}\text { obstétrica nos } \\
\text { serviços públicos. }\end{array}$ & $\begin{array}{l}\text { gestação e o parto a } \\
\text { partir de relatos de } \\
\text { puérperas }\end{array}$ & $\begin{array}{l}\text { são as principais formas de violência } \\
\text { obstétrica. }\end{array}$ \\
\hline $\begin{array}{l}\text { Violência no parto: } \\
\text { revisão integrativa. }\end{array}$ & $\begin{array}{l}\text { Identificar a produção } \\
\text { científica acerca da } \\
\text { violência contra } \\
\text { mulher no parto. }\end{array}$ & $\begin{array}{l}\text { As mulheres vivenciam e relatam condições } \\
\text { desfavoráveis e prejudiciais ao nascimento, } \\
\text { mas não reconhecem esses fatores como } \\
\text { violência, já os profissionais atribuem as } \\
\text { condutas inadequadas a falta de estrutura } \\
\text { física, condições insatisfatórias de trabalho, a } \\
\text { necessidade de organizar e controlar o } \\
\text { serviço. }\end{array}$ \\
\hline $\begin{array}{l}\text { Laceração perineal } \\
\text { associado ao uso } \\
\text { de ocitocina } \\
\text { exógena. }\end{array}$ & $\begin{array}{l}\text { Analisar a ocorrência de } \\
\text { lacerações perineais } \\
\text { associadas ao uso de } \\
\text { ocitocina sintética no } \\
\text { trabalho de parto. }\end{array}$ & $\begin{array}{l}\text { Foram utilizadas várias intervenções } \\
\text { medicalizadas, como o uso de ocitocina e } \\
\text { outras práticas desnecessárias, e a maioria } \\
\text { dessas intervenções foram realizadas por } \\
\text { profissionais médicos, e as intervenções } \\
\text { realizadas pela enfermagem obstétrica, em } \\
\text { relação ao uso de ocitocina foi prescrito pelo } \\
\text { médico. Sendo perceptível a falta de prática } \\
\text { da humanização no parto. }\end{array}$ \\
\hline \multicolumn{3}{|l|}{2018} \\
\hline $\begin{array}{l}\text { Práticas de atenção } \\
\text { ao parto normal: a } \\
\text { experiencia de } \\
\text { primíparas. }\end{array}$ & $\begin{array}{l}\text { Conhecer as práticas de } \\
\text { cuidado desenvolvidas } \\
\text { pelos profissionais de } \\
\text { enfermagem durante o } \\
\text { processo parturitivo na } \\
\text { perspectiva de mulheres } \\
\text { primíparas. }\end{array}$ & $\begin{array}{l}\text { A maioria das puérperas entrevistadas teve } \\
\text { indicação de algum método não farmacológico } \\
\text { para alivio da dor, como deambulação e banho } \\
\text { quente, além de ter direito a acompanhante, } \\
\text { mas a maioria também usou droga de indução } \\
\text { do parto, como ocitocina e realizou algum tipo } \\
\text { de procedimento invasivo, como tricotomia e } \\
\text { episiotomia. }\end{array}$ \\
\hline $\begin{array}{l}\text { Barreiras } \\
\text { facilitadores para } \\
\text { humanizar o parto } \\
\text { na Tanzânia: } \\
\text { resultados de } \\
\text { entrevistas } \\
\text { semiestruturadas } \\
\text { com parteiras e } \\
\text { obstetras. }\end{array}$ & $\begin{array}{l}\text { Explorar as percepções } \\
\text { e práticas do pessoal de } \\
\text { saúde especializado na } \\
\text { humanização do } \\
\text { atendimento ao parto na } \\
\text { Tanzânia, identificando } \\
\text { as barreiras e } \\
\text { facilitadores atuais. }\end{array}$ & $\begin{array}{l}\text { Existem obstáculos sistemáticos para que seja } \\
\text { fornecida uma assistência humanizada ao } \\
\text { parto. Algumas dificuldades se relacionam } \\
\text { com a falta de espaço. Outra dificuldade é em } \\
\text { relação as normas e práticas institucionais que } \\
\text { proibiam o envolvimento da família durante o } \\
\text { processo de nascimento, incluindo crenças } \\
\text { que limitavam a escolha da posição de } \\
\text { nascimento, bem como, tradições e cultura } \\
\text { desrespeitadas. }\end{array}$ \\
\hline
\end{tabular}

Fonte: Dados da pesquisa, 2019. 
Diante a apresentação dos principais resultados dos artigos selecionados nesta pesquisa, segue a categorização dos artigos de acordo com o local de publicação. Foi necessário fazer a categorização em dois gráficos, pois existem artigos nacionais e internacionais. No gráfico 1 , tem-se a categorização dos artigos nacionais de acordo com as regiões, e no gráfico 2 tem-se a categorização dos artigos internacionais.

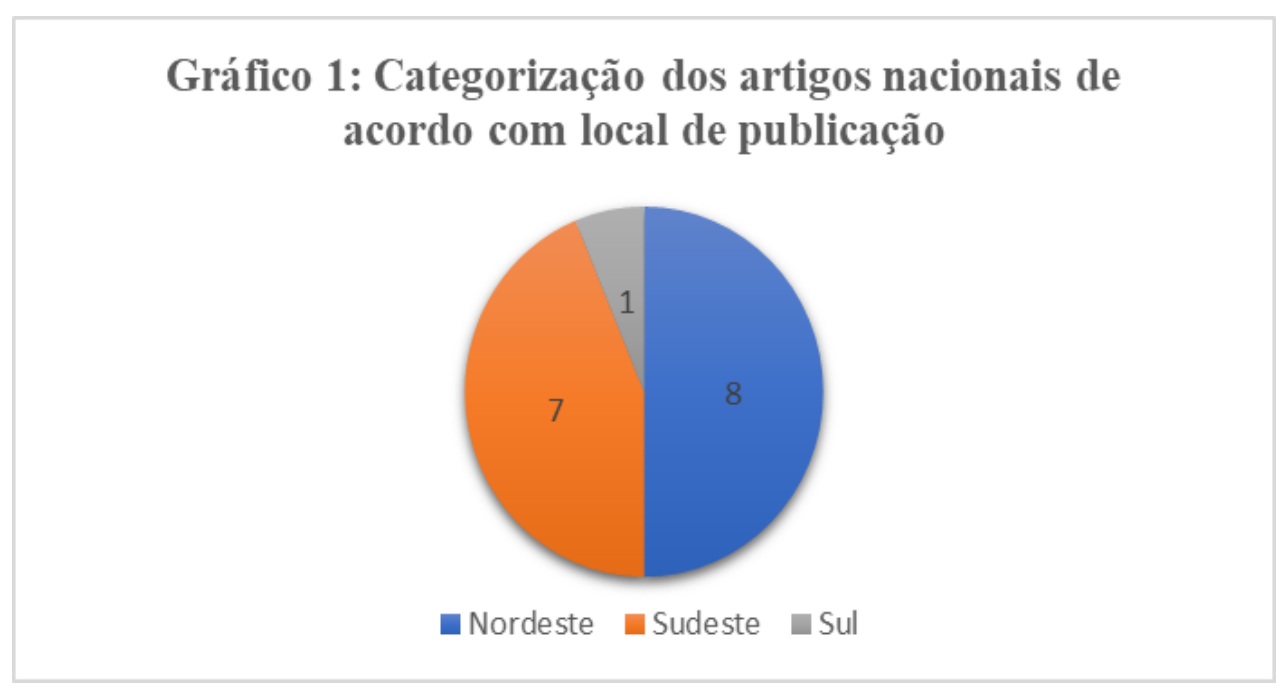

Fonte: Dados da pesquisa, 2018.

No gráfico 1, oito artigos foram publicados na região Nordeste com percentual de $50 \%$, sete na região Sudeste (44\%), e na região Sul apenas 1 artigo (6\%). No gráfico 2, um artigo foi publicado, respectivamente, na América do Sul, América do Norte e continente Africano. .

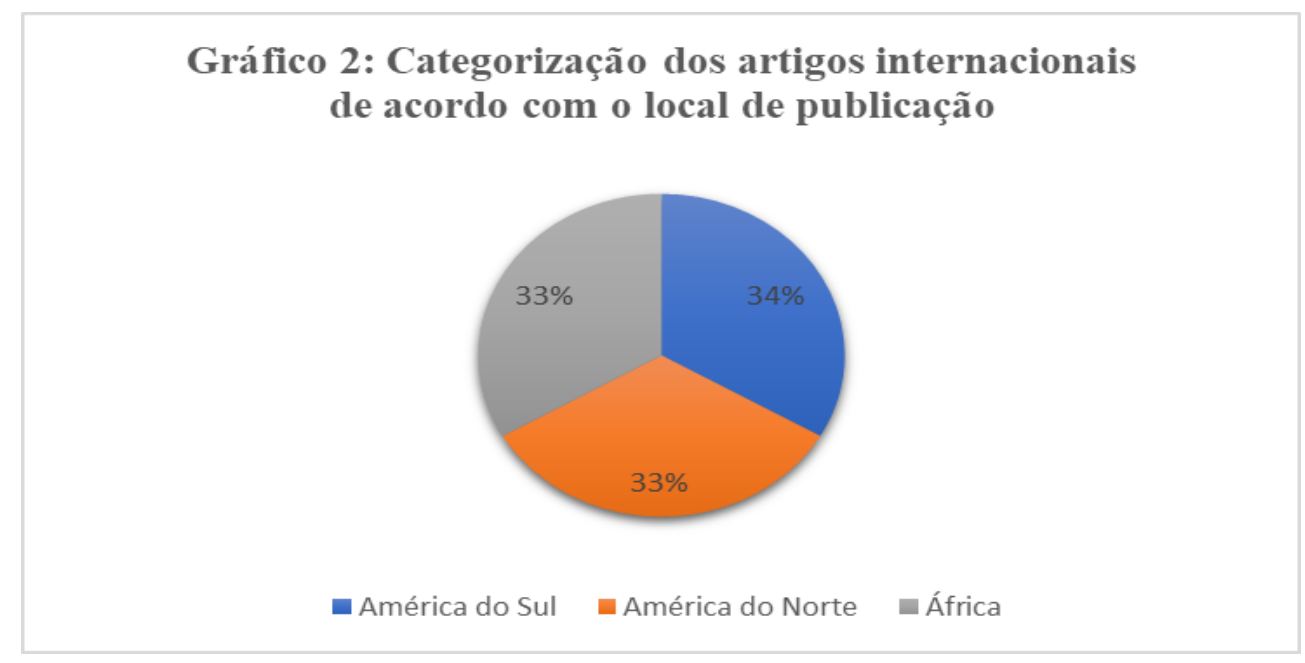

Fonte: Dados da pesquisa, 2018. 
Vale ressaltar que, a categorização é um método de organização, de um determinado universo, em grupos ou categorias, com uma finalidade específica (CARVALHO E SOUZA 2013). No caso da categorização do local de publicação dos artigos, é importante para que se tenha a dimensão da quantidade de publicação em uma determinada região, sendo relevante para compreensão da situação sobre a temática em questão em diferentes locais.

\section{Discussão}

É perceptível o quão falho é ainda a assistência dos profissionais de saúde no campo da obstetrícia, sendo visualizado pela maioria dos artigos selecionados. Envolvendo desde obstáculos sistemáticos e a própria negligência da maioria dos profissionais de saúde. Ainda se perpetua, atualmente, tipos de violência no parto, onde se encontra em alguns estudos relatos de condições desfavoráveis e que chegam a prejudicar o parto e o nascimento propriamente dito, infelizmente ainda não reconhecendo determinadas condutas como violência (GRADIM et al, 2017).

Há outro grande problema em relação ao trabalho em equipe, onde é fundamental a inserção da profissional Doula como componente essencial na humanização do parto, onde em determinados locais ainda é muito centrado no modelo biomédico, dificultando em partes, a aceitação de sugestões da profissional Doula, que vem com uma visão mais humanizada em relação a prática que já vem sendo realizada durante anos. Desse modo, outras categorias profissionais relatam que seria aceitável a presença dessa personagem se não colocasse em xeque saberes e práticas consolidadas na obstetrícia tradicional, pois muitos afirmam que a Doula não possui conhecimento técnico para questionar a prática e a conduta dos profissionais sendo "necessário" que permaneçam leigas e recuadas do conhecimento científico que os compete (HERCULANO et al, 2018).

Desse modo, é importante salientar as características do trabalho em equipe no que se refere às relações interpessoais, que estão sendo abordadas nos últimos anos de uma maneira mais intensa, no que se refere à assistência à saúde. $O$ conceito de equipe é compreendido como experiência que não se limita apenas a um conjunto de pessoas, em consequência disso, o termo 
equipe vem do coletivo, de multiplicidade de conceitos em transformação, que é caracterizado por uma rede de conexões, pelo qual os processos de produção de saúde se realizam (PERUZZO et al, 2018).

Para que haja uma efetivação das práticas de saúde, embasadas no trabalho em equipe, e para que sejam capazes de usufruir de uma cooperação mútua e harmoniosa, é preciso interação, comunicação e capacidade de empatia, entendendo e respeitando os diferentes conhecimentos particular de cada um (PERUZZO et al, 2018). Sendo de extrema importância não somente no campo da obstetrícia, mas em todos os âmbitos da saúde.

\section{Considerações Finais}

Nas pesquisas selecionadas, ficou evidenciado, com a revisão de literatura dos últimos cinco anos, que a assistência dos profissionais de saúde é de maneira geral precária, sendo a violência obstétrica algo hodierno, precisando ser debatido e enfrentado para que seja amenizado. Como foi visto, foram citados vários autores que trabalharam essa questão, e ficou notável a falta de informação em relação aos direitos das puérperas e acompanhantes durante o parto, ouve também descaso dos profissionais da saúde, manobras sem evidências científicas, comportamento insensível dos profissionais, uso de ocitocina para indução do parto, tricotomia e episiotomia. Sendo necessário que haja mudança nessa cultura, para que a mulher tenha de volta sua autonomia.

Observou-se com o estudo, que a falta de informação das puérperas é o principal motivo de existir muitos casos de violência obstétrica no pré-parto, parto e pós-parto. Um fato relevante para essa continuidade de atos, que vai contra o direito das parturientes, é que os profissionais negligenciam a importância de assegurar os direitos dessas mulheres, e ainda, outros que silenciam a prática inadequada de seus colegas.

Contudo, salienta-se que o olhar para o parto humanizado, está se incensando na atualidade, tendo a realização de técnicas adequadas. Ressalta-se que a maior parte dessas técnicas foram realizadas por enfermeiros obstetras, revelando que esses profissionais são peça chave para a mudança nesse cenário da obstetrícia baseada no modelo tradicional, onde o 
médico detém todo o saber e toda tomada de decisão. Durante a pesquisa, notou-se que existem poucos materiais publicados sobre a assistência da enfermagem obstétrica no parto humanizado em específico, sendo necessária a ampliação de estudos nessa área.

Dessa forma, cabe aos profissionais de saúde que atuam nessa área se capacitarem, para promover educação em saúde as gestantes, para que essas reconheçam e cobrem seus direitos, como, praticar a obstetrícia baseada em evidências.

\section{Referências}

ANDRADE, Pryscila de Oliveira Nascimento et al. Fatores associados à violência obstétrica na assistência ao parto vaginal em uma maternidade de alta complexidade em Recife, Pernambuco. Revista Brasileira de Saúde Materno Infantil, v. 16, n. 1, p. 29-37, jan./mar., 2016.

BALDISSEROTTO, Márcia Leonardi. Associação entre as boas práticas de assistência ao trabalho de parto e parto e a avaliação pelas puérperas do cuidado recebido. 2015. 111 f. Dissertação (Mestrado em epidemiologia e saúde pública). Fundação Oswaldo Cruz, Rio de Janeiro, 2015.

BINFA, Lorena et al. Assessment of the implementation of the model of integrated and humanized midwifery health services in Chile. Midwifery, v. 35, n. 16, p. 53-61, fev. 2016.

CARVALHO, Vanessa Franco de et al. Direitos das parturientes: conhecimento da adolescente e acompanhante. Saúde Sociedade, v. 23, n. 2, p. 572-581, abr./jun., 2014.

CHESTNUT, David H et al. Anestesia obstétrica princípios e práticas. 5. ed. Rio de Janeiro: Elsevier, 2016.

DIXON, Lydia Zacher. Obstetrics in a Time of Violence: Mexican Midwives Critique Routine Hospital Practices. Medical Antropology Quarterly, v. 29, n. 4, p. 437-454, nov. 2015. 
DODOU, Hilana Dayana; RODRIGUES, Dafne Paiva; ORIÁ, Mônica Oliveira Batista. O cuidado à mulher no contexto da maternidade: caminhos e desafios para a humanização. Revista Fundação Care, v. 9, n. 1, p. 222-230, jan./mar., 2017.

ERCOLE, Flávia Falci; MELO, Laís Samara de; ALCOFORADO, Carla Lúcia Goulart Constant. Revisão integrativa versus revisão sistemática. Revista Mineira de Enfermagem (REME), v. 18, n. 1, p. 9-11, jan./mar., 2014.

ESTRELA, Carlos. Metodologia Científica: Ciência ensino e pesquisa. 3. ed. Porto Alegre, Artes Médicas, 2018.

FERREIRA JUNIOR, Antônio Rodrigues; BARROS, Nelson Filice de. Motivos para atuação e formação profissional: percepção de doulas. Physis, v. 26, n. 4, p. 13951407, out./dez., 2016.

GRADIM, Clícia Valim Cortez et al. Violência no parto: revisão integrativa. Revista de Enfermagem UFPE, v. 11, n. 3, p. 1299-308, mar. 2017.

MAIA, Ana Carolina Mendes Soares Benevenuto. Promoção da saúde à mulher na atenção ao parto: comportamentos específicos e atuação da enfermeira no programa cegonha carioca. 2017. 141 f. Tese (Doutorado em Saúde da Mulher). Universidade Federal do Rio de Janeiro, Rio de Janeiro, 2017.

MORAIS, Jocasta Maria Oliveira; PAZ, Bruna Silva do Nascimento; BEZERRA, Sabrina Maria de Matos. Parto humanizado sob a ótica de puérperas atendidas em uma maternidade pública. Revista de Enfermagem UFPE, v. 11, n. 11, p. 4625-30, nov. 2017.

MOTTA, Sylvia Adria Martins Franco et al. Implementação da humanização da assistência ao parto natural. Revista de enfermagem UFPE, v. 10, n. 2, p. 593-599, fev. 2016.

MSELLE, Lilian T.; KOHI, Thecla W.; DOL, Justine. Barriers and facilitators to humanizing birth care in Tanzania: findings from semistructured interviews with midwives and obstetricians. Reproductive Health, v. 15, n. 137, p. 583-587, ago. 2018. 
NASCIMENTO, Laís Chaves do et al. Relato de puérperas acerca da violência obstétrica nos serviços públicos. Revista de Enfermagem UFPE, v. 11, n. 5, p. 20142023, mai. 2017.

OLIVEIRA, Lorena Bernardes de et al. Laceração perineal associada ao uso de ocitocina exógena. Revista de Enfermagem UFPE, v. 11, n. 6, p. 2273-2278, jun. 2017.

OLIVEIRA, Virgínia Junqueira. O sensível e o insensível na sala de parto: interdiscursos de profissionais de saúde e mulheres. 2017. 160 f. Tese (Doutorado em enfermagem). Universidade Federal de Minas Gerais. Belo Horizonte. 2016.

DE SÁ, Angela Mitrano Perazzini et al. O direito ao acesso e acompanhamento ao parto e nascimento: a ótica das mulheres. Revista de Enfermagem UFPE, v. 11, n. 7, p. 2683-2690, jul. 2017.

PERUZZO Hellen Emília et al. Os desafios de se trabalhar em equipe na estratégia saúde da família. Escola Anna Nery, v. 22, n. 4, p. 1-9, ago. 2018.

POSSATI, Andrêssa Batista et al. Humanização do parto: significados e percepções de enfermeiras. Escola Ana Nery Revista de Enfermagem, v. 21, n. 4, p. 1-6, ago. 2016.

SANTOS, Andressa Heringer Lohan dos et al. Práticas de assistência ao parto normal: formação na modalidade de residência. Revista de Enfermagem UFPE, v. 11, n. 1, p. 1-9, jan. 2017.

SCARTON, Juliane et al. Práticas de atenção ao parto normal: a experiência de primíparas. Revista Online de Pesquisa, v. 10, n. 1, p. 17-24, jan./mar., 2018.

SILVA, Michelle Gonçalves da et al. Violência obstétrica na visão de enfermeiras obstetras. Revista Rene, v. 15, n. 4, p. 720-8, ago. 2014.

SOUSA, Ana Maria Magalhães et al. Práticas na assistência ao parto em maternidades com inserção de enfermeiras obstétricas, em Belo Horizonte, Minas Gerais. Escola Ana Nery Revista de Enfermagem, v. 20, n. 2, p. 324-331, abr./jun., 2016. 
EDUCAÇÃO CIÊNCIA E SAÚDE | http://dx.doi.org/10.20438/ecs.v7i1.242 